\title{
O uso de filmes legendados no ensino e aprendizagem de língua estrangeira: aquisição vocabular em língua inglesa
}

The use of subtitled films in teaching and learning foreign languages: vocabulary acquisition in English

Bill Bob Adonis Arinos Lima e Sousa*

Instituto Federal de Educação, Ciência e Tecnologia do Ceará - IFCE

Universidade Federal do Ceará - UFC

Fortaleza, Ceará / Brasil

RESUMO: Este artigo trata da aquisição vocabular em língua inglesa (LI) a partir da implementação de uma rotina pedagógica, que chamamos aqui de sequência didática $(\mathrm{SD})$, orientada para uso em sala de aula de língua estrangeira (LE). Essa SD envolve o trabalho com filmes legendados e tradução escrita, na vertente funcional, e tem como foco a promoção da aquisição vocabular em LE. Para investigar a efetividade da SD, foi conduzida uma pesquisa com uma turma de ensino médio em uma escola pública de Fortaleza, no Ceará. A pesquisa mediu a aquisição vocabular em LI dos participantes, que atingiu a média percentual de 56,48\% quando considerada a partir da carência lexical (32,75\%) encontrada no pré-teste.

PALAVRAS-CHAVE: ensino; língua estrangeira; filme legendado; aquisição vocabular; tradução.

ABSTRACT: This paper addresses vocabulary acquisition in English through the implementation of a pedagogic routine, which we call here didactic sequence (DS), that is oriented to be used in foreign language (FL) classes. This DS involves the work with subtitled films and written translations in a functional perspective, focusing on vocabulary acquisition in FL. In order to investigate the effectiveness of the DS, a research was conducted with a high school class from a public school in Fortaleza, Ceará. The research measured the participant's

\footnotetext{
*bill_sousa@hotmail.com; bill.sousa@iffce.edu.br. Licenciado em Letras - português e inglês, pela Universidade Estadual Vale do Acaraú (UVA). Mestre em Estudos da Tradução, pela Universidade Federal do Ceará (UFC). Professor efetivo de língua inglesa do Instituto Federal de Educação, Ciência e Tecnologia do Ceará (IFCE).
} 
vocabulary acquisition in English, which reached the average of 56,48\% when taken from the lexical shortage $(32,75 \%)$ identified in the pre-test.

KEYWORDS: teaching; foreign language; subtitled film; vocabulary acquisition; translation.

\section{Introdução}

Vários estudos comprovam que o uso de filmes legendados no aprendizado de línguas estrangeiras (LE) traz diversos benefícios, sejam eles no desenvolvimento de habilidades escritas ou orais (ARAÚJO, 2008; CHAGAS, 2005; DANAN, 1992; GOMES, 2006; FAZILATFAR; GHORBANI; SAMAVARCHI, 2011; HSU et al., 2013; MATIELO; COLLET; D'ELY, 2013; OLIVEIRA FILHO, 2008). O que muitos desses estudos não sugerem são rotinas pedagógicas envolvendo atividades de tradução escrita que possam ser utilizadas em sala de aula de LE. Este estudo trata de uma rotina pedagógica, que chamamos aqui de sequência didática (ZABALA, 1998), orientada para uso em sala de aula de LE.

Este artigo é resultado de uma dissertação de mestrado ${ }^{1}$ que trata do uso de filmes legendados e atividade de tradução escrita como forma de ampliar o repertório vocabular em língua inglesa (LI) de alunos do Ensino Médio (SOUSA, 2016). Como aporte teórico para este estudo, usamos diversos conceitos da tradução audiovisual (CAIMI, 2009; DANAN, 2004; DÍAZ CINTAS, 2004, 2005, 2008; DÍAZ CINTAS; CRUZ, 2008; DÍAZ CINTAS; REMAEL, 2014; GAMBIER, 2006; GEORGAKOPOULOU, 2009; KRUGER, 2008; NEVES, 2004; PAVESI; PEREGO, 2008; SKUGGEVIK, 2009; ZABALBEASCOA, 2008) e da tradução funcionalista (NORD, 2001, 2005, 2006a, 2006b, 2009, 2010, 2012; REISS, 2004; VERMEER, 2004). No que se refere à tradução audiovisual (TAV), esses conceitos importam ao trabalho de avaliação da qualidade das legendas dos filmes a serem utilizados em sala de aula de língua estrangeira (LE). No que se relaciona à tradução funcionalista, seus pressupostos se aplicam ao processo de seleção e análise de textos-fonte (TF), ao encargo didático de tradução e à avaliação da qualidade das traduções dos alunos/participantes, que podem ser avaliadas sob uma perspectiva prospectiva de tradução.

${ }^{1}$ Estudo realizado sob a orientação do professor Dr. Rafael Ferreira da Silva (Universidade Federal do Ceará - UFC). 
Iniciamos este trabalho com uma breve discussão acerca dos estudos que tratam do uso de filmes legendados no ensino e aprendizagem de LE. A partir desse ponto, elencamos alguns conceitos da tradução audiovisual (TAV), mais precisamente aqueles que tratam da qualidade das legendas. $\mathrm{Na}$ seção subsequente, discutimos o uso da tradução em sala de aula de LE a partir dos pressupostos da teoria funcionalista da Tradução, com bases alemãs. Por fim, descrevemos a pesquisa realizada com os alunos de uma escola pública fortalezense, compreendendo o uso de uma sequência didática $(\mathrm{SD})^{2}$ para aquisição vocabular ${ }^{3}$ e os resultados obtidos a partir da Atividade didática de tradução, dos Pré-testes e dos Pós-testes.

\section{Legendagem e ensino e aprendizagem de LE}

A investigação sobre o uso de filmes legendados no ensino e aprendizagem de $\mathrm{LE}^{4}$ vem sendo desenvolvida, há décadas, relatando alguns

\footnotetext{
${ }^{2}$ Usamos, aqui, a expressão "sequência didática" no sentido de "um conjunto de atividades ordenadas, estruturadas e articuladas para a realização de certos objetivos educacionais, que têm um princípio [processo] e um fim conhecidos tanto pelo professor como pelos alunos" (ZABALA, 1998, p. 18, grifos do autor). Primeiramente, optamos por essa expressão porque compreendemos que outros termos como "tarefa", "atividade didática", "sequência de atividades", "proposta didática” etc. não resumem o que fazemos na parte experimental desta pesquisa. Além disso, reconhecemos o uso de SD, na definição apresentada, em vários trabalhos da área educativa, inclusive no ensino de línguas (BARROS; PEREIRA; ANDRADE, 2014; FONSECA, 2005; MAROQUI; PAIVA; FONSECA, 2015; PERETTI; TONIN DA COSTA, 2013; RIBEIRO, 2013).

${ }^{3}$ Em nosso trabalho, para fins metodológicos, os termos "aquisição" e "aprendizagem" são intercambiáveis. Porém, como o título da pesquisa evidencia, damos preferência ao termo "aquisição" por entendermos que, durante a SD aqui proposta, os alunos/participantes adquirem a LE de forma mais espontânea que formal (PAVESI; PEREGO, 2008, p. 218) ou, nas palavras de Caimi (2009, p. 246), de um modo seminatural, já que são expostos a um texto audiovisual legendado. Se por um lado não podemos afirmar, de forma categórica, que esse é um processo puramente aquisitivo, por outro, não podemos ignorar a facilidade com que os participantes desta pesquisa aumentaram o seu repertório vocabular. Além disso, houve um lapso de seis dias entre a SD e o Pós-teste, os participantes não foram instruídos a estudar o conteúdo usado no experimento e não tiveram nenhum incentivo no que se refere à pontuação para nota escolar.

${ }^{4}$ Usa-se, aqui, a expressão "língua estrangeira" (LE) como um hiperônimo, ou seja, sempre que se estiver falando de línguas que não são nativas, abarcando assim, também, a noção de segunda língua (L2) e línguas adicionais.
} 
dos fatores que influenciam essa aprendizagem, bem como os ganhos que os alunos de LE podem ter ao serem expostos a esse tipo de material. Neves (2004), por exemplo, assevera que um dos principais motivos para se usar a TAV no ensino de LE está no lúdico e na forma holística em que a língua é trabalhada. Com efeito, diversas pessoas usam os filmes como forma de entretenimento e, ao assistir a um filme legendado, estão expostas a quatro tipos de informações distintas: àquelas de ordem verbal escritas, às de ordem verbal faladas, às de ordem não verbal sonoras e às de ordem não verbal visuais (ZABALBEASCOA, 2008). São essas informações que tornam o texto ${ }^{5}$ audiovisual legendado uma ferramenta promissora ao ensino e aprendizagem de LE. No que se relaciona à aquisição vocabular, mais especificamente, Neves (2004) aponta que é exatamente a combinação de imagens e sons que facilita o aprendizado de itens lexicais contextualizados, como também a compreensão de expressões idiomáticas. Caimi (2009, p. 241, tradução nossa ${ }^{6}$ ) ratifica esse raciocínio ao afirmar que

Assistir a filmes legendados constitui-se em uma experiência comunicativa que perpassa o linguístico, já que a mensagem é simultaneamente transmitida pelos dois canais de comunicação mais comuns: falado e escrito. Consequentemente, os espectadores têm que exercitar habilidades de compreensão auditiva e leitura simultaneamente, apoiados pelos estímulos visuais e animados do enredo fílmico. ${ }^{7}$

Nesse mesmo sentido, Díaz Cintas e Cruz (2008, p. 207) asseveram que os vídeos legendados, por meio de informações contextuais, ajudam os

\footnotetext{
${ }^{5}$ Usamos neste estudo a noção de texto encontrada em Kress e van Leeuwen (2006) que, de forma recorrente, referem-se a textos verbais, sugerindo, também, a existência de textos não verbais. Os autores ampliam essa noção ao usarem os termos "objeto-texto visual" e "texto visual", explicitando essa concepção de texto por meio dos seguintes exemplos: obras de arte, mapas, gráficos e websites. Ainda, os autores põem em relação de igualdade "texto" e "mensagem", destacando, para os textos visuais, suportes como o papel, a tela (pintura) e a tela de computador.

${ }^{6}$ As traduções contidas neste trabalho são de nossa autoria e servem para fins meramente didáticos.

${ }^{7}$ No original: "Viewing subtitled films is a cross-linguistic communication experience, where the message is simultaneously conveyed by the two most common channels of communication: speech and writing. Consequently, viewers have to practice reading and listening skills simultaneously, backed up by the visual, animated input of the storyline of the film".
} 
alunos a decifrar o significado de palavras que eles não conhecem. Isso se dá, segundo os autores, pelo auxílio de informações extralinguísticas veiculadas pela imagem e pela performance dos atores na tela. Ainda de acordo com Díaz Cintas e Cruz (2008, p. 207), há de se ponderar a atividade redundante e repetitiva de processamento das mesmas palavras e frases através de dois canais distintos, o auditivo e o visual. Os autores também salientam que as palavras escritas e faladas mantêm uma relação de proximidade com o que é mostrado e atuado na tela, criando, assim, um terceiro nível de coesão semiótica em um texto audiovisual, reforçando sua compreensão por reiteração.

Ainda sobre as vantagens do uso de filmes legendados no aprendizado de LE, Díaz Cintas e Cruz (2008), Pavesi e Perego (2008), e Danan (2004) argumentam que este tipo de material pode ser uma ótima opção para atingir o que preconiza a hipótese da compreensão de Stephen Krashen. A aquisição de uma língua, seja ela a primeira ou a segunda, ocorre apenas quando a compreensão de mensagens reais acontece e quando o aprendiz não está "na defensiva" (KRASHEN, 2009, p. 6).

Para Krashen (2009, p. 21), nós adquirimos, em outras palavras, apenas quando entendemos a língua que contém uma estrutura "um pouco além" da que conhecemos. Isto pode ser conseguido com a ajuda do contexto e de informações extralinguísticas. $\mathrm{O}$ autor ainda argumenta que, se o filtro afetivo for alto/forte, ou seja, se os alunos não se sentirem seguros no ambiente de sala aula, a aquisição da LE é dificultada. Ao contrário, quando o filtro é baixo/fraco, isso significa que os alunos não têm receio, ou têm pouco receio, em participar da aula de LE, pois sentem confiança naquele ambiente.

O filme legendado facilita a compreensão do input através das informações linguísticas e extralinguísticas e, como representa uma atividade de entretenimento, pode deixar o filtro afetivo baixo (DÍAZ CINTAS; CRUZ, 2008; PAVESI; PEREGO, 2008); contudo, mesmo com o auxílio das legendas e dos recursos visuais, o input que estiver muito além da competência linguística dos espectadores poderá gerar ganhos ínfimos em LE (DANAN, 2004).

Apesar das vantagens apontadas pelos autores supracitados, na literatura examinada nesta pesquisa verifica-se a carência de estudos que objetivem maior sistematização do uso de filmes legendados em sala de aula de LE. Essa sistematização poderia ocorrer por meio da proposição 
de atividades, tarefas e SD que explorassem não apenas o material fílmico em si, mas também que estendessem esse material ao incluir outros, como exercícios de compreensão e produção, sejam escritos ou orais. Vejamos algumas pesquisas em âmbito nacional e internacional.

Araújo (2008), ao conduzir um estudo com grupos experimentais e grupos-controle com alunos de um curso de LI, verificou que os alunos expostos a filmes legendados respondiam a perguntas orais com mais facilidade e também eram mais criativos em suas repostas. Em consonância com a autora, Gomes (2006) relata sobre os participantes do grupo experimental, alunos de um curso de LI: "Constatou-se que eles falavam mais rápido e com menos pausas, expressavam-se com maior clareza e criatividade, além de apresentarem discurso mais denso" (GOMES, 2006, p. 100). Já Oliveira Filho (2008) investigou a eficácia da utilização da legendagem intralingual ${ }^{8}$ no desenvolvimento da proficiência oral em língua francesa. $\mathrm{O}$ autor concluiu que o grupo experimental também superou o grupo-controle no quesito produção oral. Chagas (2005) investigou o uso desse recurso didático, nas aulas de LI, em três turmas de quinta série de escolas públicas e percebeu que o uso da linguagem fílmica estimulou os alunos a interagir durante as aulas de LI e a fazer associações linguísticoculturais, especialmente aquelas relacionadas ao léxico.

Muitas das pesquisas que investigam a aquisição vocabular em LE também verificam a influência dos diferentes tipos de legendas: interlinguais, intralinguais e reversas. ${ }^{9}$ Matielo, Collet e D’Ely (2013) usaram legendas interlinguais e intralinguais em um experimento com alunos de um curso de LI. Os autores aplicaram, em três etapas, pré-testes, testes e pós-testes e constataram que houve maior aquisição imediata de vocabulário pelo grupo

\footnotetext{
8 A legendagem surge da necessidade de acesso. Primeiro com o uso de legendas interlinguais direcionado às pessoas que não têm acesso à língua do TF. Mais tarde, com o advento da legendagem para surdos e ensurdecidos (LSE), um dos tipos de legenda intralingual (DÍAZ CINTAS; REMAEL, 2014), contendo o texto oral e informações como ruídos e música, os quais não podem ser percebidos com clareza, de forma auditiva, pelos deficientes. Observe-se, aqui, que a legenda interlingual também pode estar a serviço do público com deficiência auditiva. O outro tipo de legenda intralingual é aquele destinado, por exemplo, ao karaokê ou aos aprendizes de LE (DÍAZ CINTAS; REMAEL, 2014). Este foi um dos tipos usado na nossa pesquisa.

${ }^{9}$ Legendas reversas são aquelas usadas nas situações em que um filme é exibido na sua versão dublada (língua materna) e com legendas em LE.
} 
exposto ao material com legendas intralinguais, embora esse mesmo grupo tenha mostrado um desempenho inferior no pós-teste, o que nos faz levantar questões sobre aquisição e aprendizado e memória de longo prazo. Essa é mais uma das lacunas nesses estudos. Danan (1992), ao testar a influência de vídeos legendados na aquisição de vocabulário com estudantes de francês, percebeu que houve maior aquisição por meio do uso de legendas reversas ${ }^{10}$ e intralinguais, quando comparado ao uso de legendas interlinguais e ao uso do vídeo sem legenda. Fazilatfar, Ghorbani e Samavarchi (2011) também estudaram o efeito das legendas reversas quando comparadas aos demais tipos. Os participantes dessa pesquisa foram aprendizes de LI. Os autores afirmam que

diferente de muitos estudos, esse estudo, que contou com um grupo-controle sem a influência das legendas, demonstrou a relativa superioridade dos programas de TV com legenda reversa em relação aos programas de TV com legendas padrão ou sem legendas, em termos de aprendizado de palavras desconhecidas. ${ }^{11}$ (FAZILATFAR; GHORBANI; SAMAVARCHI, 2011, p. 44)

Hsu et al. (2013), em consonância como os autores anteriores, investigaram o efeito de diferentes tipos de legenda na aquisição de vocabulário em LE, nesse caso também na LI. Os participantes desse experimento foram alunos da quinta série do ensino fundamental. Os resultados desse estudo indicaram um equilíbrio de aquisição vocabular entre o grupo exposto às legendas interlinguais e o grupo exposto às legendas intralinguais, e que ambos superaram o grupo que usou vídeos sem legenda. Como forma de organizar as informações que se relacionam ao objeto de interesse deste artigo, a aquisição vocabular em LE por meio de filmes legendados, dispusemos alguns dados no Quadro 1.

\footnotetext{
${ }^{10}$ Legendas reversas, em Danan (1992), significa áudio em inglês (língua materna) e legendas em francês (LE).

${ }^{11}$ No original: "unlike many studies, this study enjoying a controlling non-subtitling group demonstrated the relative superiority of reversed subtitled TV programs over standard subtitled and non-subtitled TV programs in terms of enhancing readers' learning of unknown words".
} 
QUADRO 1 - Fatores positivos à aquisição vocabular por meio de filmes

\begin{tabular}{|l|l|}
\hline \multicolumn{1}{|c|}{ Fatores de aquisição } & \multicolumn{1}{c|}{ Referencial teórico } \\
\hline Repetição de vocábulos & Pavesi e Perego (2008, p. 129); Díaz Cintas (2008, p. 207) \\
\hline Redundância (som e imagem) & Neves (2004); Díaz Cintas (2008, p. 207); Caimi (2009) \\
\hline Uso de legendas intralinguais & Danan (1992); Matielo, Collet e D’Ely (2013); Hsu et al (2013) \\
\hline Uso de legendas reversas & Danan (1992); Fazilatfar, Ghorbani e Samavarchi (2011) \\
\hline Uso de legendas interlinguais & Chagas (2005); Hsu et al (2013) \\
\hline
\end{tabular}

Fonte: Elaborado pelos autores.

Percebemos que os estudos acima destacam várias vantagens do uso de filmes legendados em sala de aula de LE. A pesquisa que descrevemos neste artigo vai ao encontro desses estudos, porém, diferencia-se das demais ao combinar o uso de dois tipos de legendas (interlinguais e intralinguais) com o mesmo grupo de participantes, o que pode ter figurado neste estudo como um fator preponderante à aquisição de vocabulário em LI. Independentemente do tipo de legenda escolhida para ser usada em sala de aula, é fundamental que se observe sua qualidade. Na seção seguinte, destacamos alguns padrões de qualidade das legendas fílmicas a serem observados, pelo professor de LE, no ato da escolha desse tipo de material didático.

\section{Qualidade das legendas}

A legenda fílmica é parte de um todo semiótico multimodal (GAMBIER, 2006). As imagens e os sons significam muito nesse tipo de texto, portanto, as legendas se coadunam a essa parte, formando um todo coeso. Partindo dessas assertivas, podemos afirmar que, se a qualidade das legendas de um vídeo não for boa, a compreensão do texto audiovisual pode ficar seriamente comprometida. Por isso, faz-se necessário que o professor de LE, ao lançar mão desse tipo de material, avalie a qualidade das legendas. Nesse sentido, abordaremos aqui alguns tópicos relacionados aos padrões técnicos de legendagem. Dentre eles, destacam-se: a sincronia, o tempo de duração das legendas, a identificação de personagens, o número e a quebra de linhas e a posição das legendas na tela. Contudo, a atividade de produção de legendas não se resume a isso.

Um dos aspectos a serem observados nas legendas interlinguais, por exemplo, é o seu caráter sintético e muitas vezes elíptico. Como expõe Skuggevik (2009, p. 197): "Essa necessidade simplificativa nasce do fato de 
as legendas não substituírem a língua original do filme, elas coexistem com ela, bem como com outros canais auditivos e visuais do filme, como também [...] competem com eles". ${ }^{12}$ Observamos, nessa argumentação, parte da complexidade dessa atividade de TAV. A esse respeito, Kruger (2008, p. 82) ressalta que

O legendador tem que negociar o número de caracteres, a duração da legenda, a quebra de linhas, as trocas de tomada e de cenas, os ritmos visuais e auditivos, o alinhamento entre o que é dito com o momento em que é dito (sincronização), os espaços entre as legendas e os vários sistemas semióticos que impactam no que é legendado e na forma como se legenda. ${ }^{13}$

Soma-se a isso, certamente, o registro linguístico que sofre uma transmutação do oral para o escrito, requerendo, dessa forma, adequações. Há, ainda, momentos em que as legendas são simplesmente dispensáveis pelo fato de a cena significar por si só, especialmente nos casos em que há a repetição de falas, como nos filmes policiais em que um comando é repetido várias vezes. ${ }^{14}$ No que concerne à sincronia, observe-se o que Díaz Cintas (2005) chama de regra de ouro da legendagem: a legenda deve coincidir com o início e o final de um segmento discursivo. ${ }^{15} \mathrm{O}$ autor também nos orienta sobre o tempo de permanência de uma legenda na tela:

Se uma legenda permanece na tela por muito tempo, o espectador tende a relê-la. Para evitar essa situação, recomenda-se seis segundos como tempo máximo de exposição de legendas com duas linhas cheias. Por um outro lado, se a legenda permanece na tela por muito pouco tempo, os espectadores não terão tempo de ler a informação. Por isso, convencionou-se que o tempo mínimo de exposição para uma legenda

\footnotetext{
${ }^{12}$ No original: "This need to simplify arises because subtitles do not replace the original language of the film, they coexist with it, as well as with the other audio and visual channels of the film, and even $[\ldots]$ compete with them."

${ }^{13}$ No original: "The subtitler has to negotiate between number of characters, duration of subtitles, line divisions, shot and scene changes, visual and auditory rhythm, alignment of what is said with when it is said (synchronicity), gaps between subtitles, and various semiotic sign systems that impact on what is subtitled and how it is subtitled."

${ }^{14}$ Cf. Carroll e Ivarsson (1998), Code of Good Subtitling Practice, Subtitle Spotting and Translation, item número 13.

${ }^{15}$ Cf. Ibid., item número 21.
} 
deveria ser um segundo, independente de quão curta ela possa ser. Se a informação permanecer na tela por menos tempo, corre-se o risco dela aparecer como um flash e de os espectadores não conseguirem lê-la. ${ }^{16}$ (DÍAZ CINTAS, 2008, p. 95).

Ademais, Díaz Cintas (2005) destaca a necessidade de se identificar as falas dos personagens quando ocorre sua concomitância na tela. Nesse caso, a primeira linha é reservada ao personagem que fala primeiro na cena, e a segunda linha, que é sempre precedida de travessão, ao segundo personagem. $\mathrm{O}$ autor também explica ser comum ambas as linhas virem precedidas de travessão. ${ }^{17}$ Acerca da quantidade de linhas, Díaz Cintas e Remael (2014) lecionam que geralmente se usa um total de duas linhas ${ }^{18} \mathrm{com}$ uma variação de 32 a 41 caracteres por linha.

De acordo com Georgakopoulou (2009), a forma como as legendas são dispostas na tela influenciam bastante sua leitura. ${ }^{19} \mathrm{~A}$ autora explica que "Mesmo a quebra de linhas em uma única legenda pode facilitar a compreensão e aumentar a velocidade de leitura, se a segmentação for feita respeitando-se grupos nominais e verbais de uma frase ou oração, ao invés de fracioná-los em unidades menores"20 (GEORGAKOPOULOU, 2009, p. 24). Na Figura 1, a autora expõe a questão de forma prática com um exemplo de uma legendagem intralingual (filme Mulher nota 1000):

\footnotetext{
${ }^{16}$ No original: "If a subtitle stays on screen too long, the viewer tends to re-read it. To avoid this situation, six seconds is the recommended maximum exposure time to keep a full two-liner on screen. On the other hand, if a subtitle stays on screen too little, viewers will not have the time to read the information, and this is why it is generally agreed that the minimum exposure time for a subtitle should be one second, irrespective of how short the actual subtitle may be. If the information stays on screen less time, the risk is run that it will appear as a flash and viewers will not be able to read it".

${ }^{17}$ Cf. Carroll e Ivarsson (1998), Code of Good Subtitling Practice, "Technical Aspects", item número 2, letra $\mathrm{C}$.

${ }^{18}$ Cf. Carrol e Ivarsson (1998), "Subtitle Spotting and Translation”, item número 19.

${ }^{19}$ Cf. Carrol e Ivarsson (1998), "Subtitle Spotting and Translation”, item número 6.

${ }^{20}$ No original: "Even appropriate line breaks within a single subtitle can facilitate comprehension and increase reading speed if segmentation is done into noun or verb phrases, rather than smaller units of a sentence or clause".
} 
FIGURA 1 - Disposição da legenda em linhas

\begin{tabular}{|c|c|}
\hline \multicolumn{2}{|c|}{ Original dialogue } \\
01.03.53.01 & 01.03.57.11 \\
\hline Option 1 & Option 2 \\
\hline I don't understand. How come your parents trust you all of a sudden? \\
\hline Oph't understand why your & I don't understand why your parents \\
parents trust you all of a sudden. & trust you all of a sudden. \\
\hline
\end{tabular}

Fonte: Georgakopolou (2009, p. 24)

Sobre a posição das legendas, Carroll e Ivarsson (1998) argumentam que essas devem vir centralizadas, evitando-se, por exemplo, a interferência de logotipos televisivos nos cantos da tela. Os tópicos elencados nesta seção certamente não encerram todas as variáveis envolvidas nessa modalidade de TAV. Para um conhecimento mais detalhado dos demais elementos que permeiam e influenciam a legendagem de filmes, faz-se necessário um estudo mais aprofundado. Por ora, as orientações apresentadas podem servir como suporte para fundamentação da escolha de materiais didáticos audiviosuais legendados. Entretanto, escolher um filme legendado não se resume em avaliar a qualidade de sua legenda; outros fatores entram em jogo (produção, recepção, função etc.). A teoria funcionalista da Tradução, ao prever uma investigação compreensiva do texto-fonte (TF), pode ser útil, também, na seleção de filmes.

\section{$4 \mathrm{O}$ uso da teoria funcionalista da Tradução em sala de aula de LE}

Diversos preceitos da teoria funcionalista da Tradução podem ser usados para orientar o trabalho do professor de LE. A visão funcional da tradução, com bases alemãs, tem suas primeiras publicações com os trabalhos de Justa Holz-Mänttäri, Hans Vermeer e Katharina Reiss. Christiane Nord, a partir dos conceitos de seus compatrícios, desenvolveu uma teoria forte de tradução funcionalista que abrange os conceitos de "escopo", oferta de informação, tradução prospectiva, encargo de tradução, lealdade e funções e subfunções textuais. A autora ainda propõe um modelo de análise textual direcionado à tradução.

A visão prospectiva da tradução se contrapõe às abordagens retrospectivas ou filológicas que predominaram até meados da década 
de 1970 (SNELL-HORNBY, 2010, p. 366-367). Na ótica retrospectiva, o texto de tradução (T'T) mantém uma posição servil em relação ao TF. Nesse tipo de abordagem os aspectos linguísticos do texto de partida ${ }^{21}$ ganham grande relevo. O que se observa, assim, é uma relação de servilismo em que, na língua de chegada, o tradutor deve encontrar itens lexicais capazes de substituir aqueles da língua de partida. A abordagem prospectiva, por sua vez, orienta que se deve dar maior relevo aos elementos extralinguísticos que estão envolvidos na ação tradutória ${ }^{22}$ (NORD, 2006a), podendo o tradutor exercer maior liberdade na produção do texto de chegada já que este não está inteiramente subordinado à materialidade do texto de partida.

Um dos conceitos mais caros da tradução funcionalista é a teoria do escopo (VERMEER, 2004). Para os funcionalistas, a tradução é uma ação que está condicionada a um objetivo, o escopo. O objetivo da tradução, dessa forma, orienta o trabalho do tradutor. O texto de partida, nesse contexto, é entendido como uma oferta de informação e o texto de tradução (T'T) é, também, uma oferta de informação que mantém uma relação com TF. Os níveis de literalidade e de liberdade que o tradutor usará durante o seu trabalho dependerá do escopo de tradução (VERMEER, 2004; NORD, 2001, 2005).

A negociação (entre cliente e tradutor) do objetivo da tradução e da forma como esta será feita é chamada de encargo de tradução. O encargo de tradução orientará todo o processo tradutório, pois, uma vez acordado o encargo, o tradutor observará nele as instruções para produção do TT (NORD, 2005). Da mesma forma, na perspectiva funcionalista da tradução, faz-se necessário também observar o princípio de lealdade a fim de não se produzir qualquer T'T com base apenas naquilo que foi decidido como escopo e encargo.

\footnotetext{
${ }^{21}$ Nos Estudos da Tradução, os termos "texto-fonte" e "texto de partida" são intercambiáveis; assim como, por outro lado, "texto-alvo", "texto de tradução" e "texto de chegada".

${ }^{22}$ A tradução em Nord é uma ação comunicativa intercultural, por isso a expressão “tradução intercultural" é recorrente em sua teoria, noção da qual compartilhamos neste trabalho. Em poucas palavras a autora resume dois aspectos conceituais de interesse em seu trabalho, quando diz "A língua é uma parte intrínseca de uma cultura, principalmente se cultura for definida como uma 'totalidade de conhecimentos, competências e percepções"'. (SNELL-HORNBY, 1988, p. 40 apud NORD, 2001, p. 23).
} 
Lealdade, diferente de fidelidade, mais uma vez toma um caráter prospectivo. A lealdade tradutória está exatamente na observação do respeito aos partícipes da ação comunicativa, a saber: o autor do TF, que não pode ter o seu texto manipulado de qualquer forma (respeito à produção intelectual); o iniciador (contratante do TT, cliente), que espera o respeito ao que foi acordado no encargo de tradução; o receptor (público de chegada), que tem expectativas em relação ao T'T; e o próprio tradutor, que deve ter princípios profissionais para não incorrer naquilo equacionado ao mercenarismo, isto é, produzir qualquer T'T com base apenas em um escopo de tradução (NORD, 2006a). Aqui, a materialidade do texto não é desconsiderada, mas as pessoas envolvidas nessa ação, bem como o contexto ${ }^{23}$ comunicativo, ganham relevo ${ }^{24}$ (NORD 2006a).

No que se refere às funções e subfunções textuais, Nord (2001; 2009; 2010), baseada nos trabalhos de Bühler e Jakobson, explica haver quatro tipos principais de funções e vários tipos de subfunções. Como funções textuais, sejam para os TF ou para os TT, a autora elenca a função referencial, a expressiva, a conativa e a fática. Em cada uma dessas funções, podemos encontrar subfunções como informar, entreter, emocionar, ensinar etc. A autora ainda destaca que, com exceção dos textos puramente fáticos, raramente encontramos textos com uma única função, o que se percebe, por outro lado, são hierarquias de funções que podem ser identificadas analisando-se os marcadores de função, sejam eles verbais ou não verbais.

Reiss (2004) leciona que, em um TT orientado pelo viés funcionalista, a manutenção da função do TF está subordinada ao escopo de tradução. Caso se objetive manter a mesma função do texto de partida no T'T, alcançase o que a autora chama de equivalência funcional. Na outra situação, em que

\footnotetext{
${ }^{23}$ Consideramos "contexto", neste trabalho, na perspectiva bakhtiniana. Assim, o conceito de contexto que usamos leva em consideração as situações comunicativas mais imediatas como também as situações mais amplas ou sócio-históricas (BAKHTIN, 2006, p. 112-130). ${ }^{24}$ De forma ilustrativa, Nord (2009, p. 210-211) supõe uma situação, em Jacarta, em que alguém que não domina a língua indonésia pede a uma amiga que solicite informações a um policial sobre determinado endereço. Esse policial, mesmo não sabendo onde fica o lugar, fornece uma descrição detalhada de como encontrar o tal endereço, porque em sua cultura eles evitam dizer que não sabem. A amiga em questão conhece tanto a língua como a cultura indonésia e traduz a explicação elaborada do policial como "ele não sabe onde fica".
} 
se muda no TT a função do TF, tem-se uma adequação à função estrangeira, o que Nord (2009) chama de tradução heterofuncional.

Note-se que os pressupostos da teoria funcional dão instrumentos para que, em sala de aula de LE, professores e alunos possam produzir TT com maior liberdade, rompendo a relação histórica de servilismo entre TF e texto-alvo. Essa ruptura pode ser produtiva ao aprendizado de LE, por exemplo, na tradução de idiomatismos. Ao acessar e analisar um idiomatismo na LE, o aprendiz pode ter maior liberdade linguístico-cultural para produzir o seu TT, valorizando, assim, as suas próprias língua e cultura ao produzir textos em língua materna mais idiomáticos. É fundamental, nesse ponto, que os aprendizes entendam que a língua é apenas parte de uma cultura maior e que a produção de TF e TT é circunstanciada por contextos culturais e sócio-históricos mais amplos (NORD, 2006b, 2012).

Observe-se, ainda, que na abordagem funcionalista da tradução, enunciados do tipo "leia e traduza" não são aceitáveis. Portanto, é necessário que, em sala de aula de LE, o professor forneça ou negocie com os alunos encargos de tradução claros, definidos nessa teoria como "encargo didático de tradução" (NORD, 2009, p. 232). Ademais, ao avaliar os TT dos alunos, o professor pode, baseado nos princípios funcionais, argumentar sobre a qualidade e funcionalidade dessas traduções. Por fim, consideremos o que Nord (2005) propõe como modelo de análise textual direcionado à tradução: uma investigação abrangente tanto dos elementos intratextuais quanto dos elementos extratextuais do TF.

Algumas perguntas guiam esse processo de análise. Para examinar os aspectos extratextuais, questiona-se sobre o autor e o emissor do TF, "quem?”; sobre as intenções do autor/emissor do TF, "para que?”; sobre o público/receptor ao qual o TF é direcionado, "para quem”?; sobre a mídia ou o suporte pelo qual o TF é comunicado, "por que meio?”; sobre o lugar e o tempo de produção do TF, “onde?” e "quando?”; e sobre o motivo de comunicação do TF, “por que?”. A conjunção das informações obtidas através desses questionamentos nos direciona a uma resposta para a pergunta que toca a função do TF: “com que função?” (NORD, 2005, p. 42).

Já a análise dos fatores intratextuais do TF é feita indagando-se sobre o tema do texto, "qual é o assunto?"; sobre o conteúdo do texto, “o que o texto traz?”; sobre as pressuposições de conhecimento feitas pelo autor em relação ao seu público, "que conhecimento o leitor tem/não tem?”; sobre a composição ou construção do texto, “qual é a ordem?”; sobre o 
elementos não linguísticos ou paralinguísticos que acompanham o texto, "que elementos não verbais são usados?"; sobre as características lexicais e sintáticas encontradas no texto, "que palavras são usadas?" e "que tipo de frases são usadas?"; e sobre as características suprassegmentais de entonação e prosódia, “qual é o tom?” (NORD, 2005, p. 42).

Esses tipos de análise, como mencionado anteriormente, importa à seleção de material didático, mas também à contextualização e desenho de atividades, tarefas ou SD envolvendo tradução. Ao analisar um TF seguindo o modelo nordiano, o professor de LE pode avaliar a qualidade do material a ser usado para fins didáticos, no nosso caso, os filmes legendados. Ele pode também se apropriar, de uma forma compreensiva, do TF e, a partir disso, propor encargos didáticos de tradução melhores. Vejamos como isso foi feito na pesquisa com alunos do ensino médio público de uma escola fortalezense.

\section{Aquisição vocabular em LE por meio do filme Gifted Hands}

Nossa pesquisa $^{25}$ (SOUSA, 2016) foi realizada com 20 alunos do $1^{\circ}$ ano do curso Técnico em Finanças integrado ao Ensino Médio da Escola Estadual de Educação Profissional Professor Onélio Porto, em Fortaleza, Ceará. As turmas dessa escola são compostas por jovens de ambos os sexos, na faixa etária entre 14 e 18 anos, havendo um número médio de 40 alunos por sala (dados coletados na própria instituição). Todos os participantes tiveram o consentimento dos responsáveis legais para participação na pesquisa por meio do Termo de Consentimento Livre e Esclarecido (TCLE) para responsáveis legais. Os participantes desta pesquisa se propuseram, sem nenhum constrangimento, a tomar parte nela, assinando o Termo de

\footnotetext{
${ }^{25}$ Quanto aos seus objetivos, nossa pesquisa é descritiva porque descreve e estabelece relações entre variáveis buscando identificar a natureza dessas relações (GIL, 2002). Entre os objetivos de uma pesquisa descritiva podem estar: "familiarizar-se com um fenômeno ou descobrir nova percepção do mesmo” (FONSECA, 2012, p. 22). Quanto ao seu delineamento, ela é pré-experimental, subtipo da pesquisa experimental. Nossa pesquisa determina objetos de estudo e seleciona variáveis capazes de influenciá-los, bem como define as formas de controle e de observação dos efeitos que as variáveis produzem nos objetos. "Trata-se, portanto, de uma pesquisa em que o pesquisador é um agente ativo, e não um observador passivo" (GIL, 2002, p. 47). Gil (2002) recomenda a classificação das pesquisas que não fazem uso de grupo-controle (além do grupo-experimental) como pré-experimentais.
} 
Assentimento Livre e Esclarecido (TALE). Ainda, nenhum dos participantes apresentou queixas ao professor-pesquisador ou aos seus responsáveis em relação a: 1) ser portador de surdez; 2) ser portador de cegueira dos dois olhos; 3) sofrer de algum impedimento psíquico grave - necessidades especiais que poderiam causar-lhes desconforto durante o experimento.

Os instrumentos usados para a coleta de dados foram dois questionários, uma "Atividade didática de tradução", um Pré-teste e um Pósteste. O Questionário 1 traz perguntas sobre dados pessoais dos participantes como idade, sexo e hábitos de estudo. O Questionário 2 contém perguntas acerca do contato dos participantes com filmes legendados e das opiniões deles em relação à SD. A Atividade didática de tradução é composta por legendas intralinguais de duas cenas (13 legendas, totalizando 19 linhas). O Pré-teste e o Pós-teste contêm, cada um, vinte questões que visam avaliar o conhecimento vocabular. Observa-se que as questões usadas no Pré-teste são as mesmas do Pós-teste.

Esses instrumentos estão, em sua maioria, organizados em questões objetivas. Neles os participantes podiam escolher entre opções do tipo "a/b/c/d/e", "sim/não" ou "ruim/bom/regular/ótimo" e, em algumas questões, eles podiam também acrescentar itens dando subjetividade às suas repostas. Dessa objetividade, excetua-se a Atividade didática de tradução porque nela os participantes escrevem o que acham ser a melhor forma de traduzir cada parte da legenda intralingual do filme.

O filme escolhido para este estudo foi Gifted Hands (Mãos talentosas). Essa escolha justifica-se pelos seguintes aspectos: é um filme educativo, pois narra a história de um estudante de classe baixa que se destacou em seu meio profissional por sua dedicação aos estudos - o que ilustra a importância da instrução na vida do ser humano; não apresenta o uso de linguagem ou cenas inapropriadas à faixa etária dos alunos (censura: 12 anos); discute a influência da mídia no cotidiano das pessoas, assunto de debate nos dias atuais.

As cenas ${ }^{26}$ escolhidas para uso na SD mostram o momento em que a mãe de Bennie (Ben Carson, nessa obra de ficção) vai à casa de um professor universitário fazer uma faxina. Lá, depara-se com uma situação que a faz tomar uma medida transformadora para a vida de seus filhos.

\footnotetext{
${ }^{26} \mathrm{O}$ tempo total de duração das duas cenas é de 1 minuto e 40 segundos (23'36" - 25'16”) e o número de palavras das legendas intralinguais (TF usado na atividade de tradução escrita) é de 78 .
} 
Essas duas cenas foram escolhidas, principalmente, pelos seguintes aspectos: representam um momento central da narrativa fílmica no que se refere ao seu tema; nelas, encontramos idiomatismos; os recursos de focalização e movimento da câmera veiculam uma mensagem de valorização à educação; as falas dos personagens não são rápidas, se comparadas a muitas outras cenas dessa narrativa. A escolha desse último aspecto visa facilitar a compreensão textual.

O experimento consistiu de três etapas. Na primeira etapa foram aplicados o Questionário 1 e o Pré-teste, uma avaliação composta por 20 questões objetivas (a/b/c/d/e) cujo propósito foi testar o conhecimento dos participantes sobre 19 vocábulos (verbos, substantivos e adjetivos) e uma locução verbal da LI (todos retirados da legenda intralingual das cenas fílmicas usada na SD), ou seja, vinte itens lexicais.

A segunda etapa foi a aplicação da SD. Nesta, os participantes assistiram a duas cenas do filme Gifted Hands, com legendas em português no primeiro momento e, logo após, com legendas em LI. A seguir, traduziram, com o auxílio de dicionários bilíngues impressos e do professor-pesquisador, as falas das personagens dessas cenas (legenda intralingual) por meio da Atividade didática de tradução e ao final discutiram, em grupo, suas propostas de tradução ${ }^{27}$. Dessa forma, os participantes tiveram acesso a um texto audiovisual, foram expostos à LE falada e escrita cumprindo funções e subfunções específicas (entre elas, entreter), tiveram acesso a um material autêntico ${ }^{28}$, contextualizado e traduzido e, por fim, tiveram acesso, também, à versão escrita das falas dos personagens na LE.

A terceira etapa do experimento resumiu-se à aplicação do Pósteste, que é uma cópia do Pré-teste e visa medir a aquisição vocabular dos participantes após a SD, e à aplicação do Questionário 2, com perguntas

\footnotetext{
${ }^{27}$ Apesar de já haverem assistido às cenas e lido as traduções propostas pelos tradutores/ legendadores, os participantes, ainda assim, tiveram a oportunidade de construir e reconstruir um novo texto em língua materna, que é a sua própria proposta de tradução, comparando-a, ao final, com as propostas de seus pares em plenária. Os participantes gastaram aproximadamente 25 minutos para resolver essa atividade. A consulta aos dicionários e ao professor-pesquisador foi feita esporadicamente durante esse tempo. No momento de discussão em grupo, plenária, os participantes, em sua maioria, mostraram-se ávidos por falarem suas sugestões de tradução.

${ }^{28}$ Conceituamos material autêntico como aquele que não foi produzido para fins primeiramente didáticos.
} 
acerca do contato dos participantes com filmes legendados e sobre a opinião deles em relação à SD. Essas etapas se realizaram em três dias. Entre a aplicação do Pré-teste e do Pós-teste houve um lapso de sete dias.

Por meio do aporte teórico da TAV, verificou-se a qualidade das legendas do filme com base nos padrões supramencionados. O filme Gifted Hands traz legendas interlinguais e intralinguais com ótima qualidade, o que pode ter figurado como um fator preponderante à facilidade com a qual os participantes compreenderam o texto audiovisual e resolveram a Atividade didática de tradução. A partir da teoria nordiana de análise textual (NORD, 2005), fez-se também uma investigação do filme enquanto TF. Investigou-se acerca dos elementos autor, emissor, tema, conteúdo, composição textual, elementos não verbais, campo lexical etc. A relevância desses dados está na avaliação do filme como material didático e na sua interpretação global. Com base nessa investigação, o professor-pesquisador pôde contextualizar oralmente o filme para os participantes da pesquisa, antes da exposição das cenas e da resolução da Atividade didática de tradução (atividade de tradução escrita).

Os demais pressupostos funcionalistas da Tradução discutidos aqui orientaram a execução da atividade de tradução escrita. Com base no conceito de encargo didático de tradução, o professor-pesquisador orientou os participantes a produzirem TT para fins de aprendizado. Assim, os participantes foram informados que não se esperava textos com ótima qualidade de tradução e que o erro em seus T'T era algo natural e previsível. Também, os participantes foram orientados a produzir traduções idiomáticas, ou seja, em suas decisões eles não deveriam, necessariamente, procurar equivalentes lexicais entre as línguas de partida e de chegada. Ainda, os participantes foram informados que seus TT seriam produzidos para serem discutidos em grupo (escopo). A avaliação dos TT dos participantes foi orientada pelo princípio da fidelidade.

No Quadro 2, observam-se algumas propostas de tradução dos participantes. Percebeu-se que eles, com base no contexto, produziram TT que não estão subordinados aos aspectos meramente linguísticos do TF. Verifica-se esse desprendimento, por exemplo, na tradução da expressão "What about it?". Nesse momento do filme, o professor entra em cena e fala com a mãe de Bennie. Ele diz: "The kitchen floor". Ela, naturalmente, não entende, pois falta o restante da informação sobre o piso da cozinha. Então, ela pergunta: "What about it?". Esse é um exemplo de tradução de idiomatismos por meio da SD proposta no presente estudo. 
QUADRO 2 - Amostras da cena 2

\begin{tabular}{|c|c|c|}
\hline $\begin{array}{c}\text { Legenda intralingual } \\
\text { (TF) }\end{array}$ & $\begin{array}{c}\text { Legenda intralingual } \\
\text { (TT do filme) }\end{array}$ & $\begin{array}{c}\text { Amostras dos TT dos } \\
\text { participantes }\end{array}$ \\
\hline What about it? & O que tem? & $\begin{array}{c}\text { O que tem? } \\
\text { O que aconteceu? } \\
\text { O que houve? }\end{array}$ \\
\hline
\end{tabular}

Fonte: Elaborado pelos autores.

Sobre o resultado de suas propostas de tradução coletadas por meio da Atividade didática de tradução, podemos dizer que, de uma forma geral, tratam-se de traduções aceitáveis e também funcionais. Aceitáveis porque os T'T estão coesos, coerentes e se adequam ao contexto do texto fílmico. Textos inteiramente inteligíveis. Funcionais porque os participantes aderiram às instruções dadas pelo professor-pesquisador (encargo didático de tradução), a saber: desenvolveram a tradução com objetivos didáticos; consideraram o elemento "receptor" em suas decisões tradutórias ao usar um vocabulário compatível com os seus pares; não se prenderam ao aspecto linguístico e resolveram questões como a tradução de expressões culturalmente marcadas de uma forma idiomática e funcional.

Esse desprendimento linguístico, talvez seja uma das principais características das traduções propostas pelos participantes desta pesquisa. Ao interpretar o contexto das cenas fílmicas, eles resolveram problemas de tradução sem uma preocupação exagerada com a correspondência lexical, fosse de significado ou em número de palavras. Autores como Pavesi e Perego (2008) argumentam que essa relação de um para um, nas legendas fílmicas, pode ser benéfica ao aprendizado de LE. Apesar de concordarmos parcialmente com as autoras, entendemos que, desde o início, os aprendizes de LE podem se beneficiar de teorias com foco pragmático, como a corrente de tradução funcionalista.

No caso específico desta SD, os participantes receberam instruções claras para traduzir significados (a partir do contexto ao qual tiveram acesso) antes de palavras, reforçando o caráter polissêmico das últimas. Ou seja, ao concordarem com o encargo didático de tradução (orientações do professorpesquisador em sala de aula, figurando como o iniciador, o cliente) seguiram, com certa liberdade, os termos nele constantes, tendo em mente o objetivo da tradução (escopo). Uma abordagem prospectiva de tradução, portanto.

Isso não significou que os participantes devessem menosprezar o texto de partida e seus aspectos linguísticos. Pelo contrário, entendido como 
uma oferta de informação, o TF, em grande medida, orienta a produção de uma nova oferta de informação na cultura de chegada. O que ficou patente, entretanto, no encargo didático de tradução é que os aspectos pragmáticos (contextuais) deveriam se sobrepor àqueles linguísticos. Assim, a lealdade tradutória residiu no respeito aos participantes da ação comunicativa.

Esta pesquisa demonstrou uma aquisição vocabular expressiva. Ao comparar os Pré-testes e Pós-testes (Tabelas 1 e 2), verificamos a aquisição vocabular de 56,48\% dos itens que compõem a carência lexical dos participantes $(32,75 \%)$. Chamamos de carência lexical o total de itens errados que os participantes assinalaram, no Pré-teste, ao não entenderem o significado dos vocábulos no contexto frasal.

TABELA 1 - AQV com base na carência lexical

\begin{tabular}{l|c|c|c}
\hline Itens lexicais & $\begin{array}{c}\text { Total de erros de itens } \\
\text { no PT }\end{array}$ & Itens adquiridos no PTE & AQV \\
\hline PROFESSOR & 1 & 1 & $100 \%$ \\
SPARKLES & 7 & 6 & $85,71 \%$ \\
LADY & 6 & 5 & $83,33 \%$ \\
FLOOR & 14 & 11 & $78,57 \%$ \\
KITCHEN & 4 & 3 & $75,00 \%$ \\
LAST & 13 & 9 & $69,28 \%$ \\
BOOK & 3 & 2 & $66,66 \%$ \\
WIFE & 11 & 7 & $63,63 \%$ \\
DO & 7 & 4 & $57,14 \%$ \\
CAN & 11 & 6 & $54,54 \%$ \\
SICK & 13 & 7 & $53,84 \%$ \\
JOB & 4 & 2 & $50,00 \%$ \\
GOOD & 2 & 1 & $50,00 \%$ \\
LATE & 10 & 4 & $40,00 \%$ \\
READ & 6 & 2 & $33,33 \%$ \\
TAKE CARE & 9 & 3 & $33,33 \%$ \\
WOMAN & 5 & 1 & $20,00 \%$ \\
CURIOUS & 1 & 0 & $0 \%$ \\
NEW & 1 & 0 & $0 \%$ \\
BEST & 3 & 0 & $0 \%$ \\
\hline \multicolumn{1}{c}{400} & & 74 & $56,48 \%$ \\
\hline
\end{tabular}

PT - Pré-teste PTE - Pós-teste AQV - Aquisição vocabular

Fonte: Elaborada pelos autores.

A carência lexical é analisada, aqui, individualmente e coletivamente. Individualmente, o participante poderia demonstrar uma carência lexical de até vinte itens $(100 \%)$, caso tivesse respondido de forma errada todo o Pré- 
teste. Coletivamente, os participantes poderiam demonstrar uma carência lexical de até 400 itens (100\%), se todos eles tivessem respondido de forma errada todos itens dos Pré-testes (Tabela 2).

TABELA 2 - Aquisição de itens lexicais (pela carência total)

\begin{tabular}{lc}
\hline Total de itens lexicais examinados por participante & 20 \\
Total de participantes & 20 \\
Total de itens lexicais & 400 \\
Total de erros de itens no PT(Carência lexical total) & 131 \\
Carência lexical total & $32,75 \%$ \\
Total de itens adquiridos no PTE & 74 \\
Total de AQV por item adquirido $\quad$ PTE - Pós-teste & AQV - Aquisição vocabular \\
\hline PT - Pré-teste $\quad$ PTo & \\
Fonte: Elaborada pelos autores. &
\end{tabular}

Dos vinte itens lexicais usados nos testes, houve aproveitamento de dezessete itens, comprovado pelo Pós-teste. Os participantes que, no Préteste, erraram as palavras curious, new e best mostraram um aproveitamento de $0 \%$ no Pós-teste (Tabela 1). Observou-se que alguns dos dezessete itens lexicais foram adquiridos com maior facilidade. É o caso, por exemplo, das palavras: lady, last, do, book e wife. Com base nas teorias da TAV e nas pesquisas de caráter experimental investigadas neste estudo, consideramos que os fatores "repetição", "redundância" e "combinação dos tipos de legendas" promoveram a aquisição desse vocabulário (Quadro 3).

QUADRO 3 - Fatores positivos à aquisição vocabular por meio do filme Gifted Hands

\begin{tabular}{|l|c|c|l|}
\hline Fatores de aquisição & $\begin{array}{c}\text { Itens } \\
\text { lexicais }\end{array}$ & $\begin{array}{c}\text { Média percentual de } \\
\text { aquisição dos itens }\end{array}$ & \multicolumn{1}{|c|}{ Referencial teórico } \\
\hline Repetição de vocábulos & lady, last, do & $69,91 \%$ & $\begin{array}{l}\text { Pavesi e Perego (2008, p. 219); } \\
\text { Díaz Cintas (2008, p. 207) }\end{array}$ \\
\hline $\begin{array}{l}\text { Redundância } \\
\text { (som e imagem) }\end{array}$ & book, wife & $65,14 \%$ & $\begin{array}{l}\text { Neves (2004); Díaz Cintas } \\
\text { (2008, p. 207); Caimi (2009) }\end{array}$ \\
\hline $\begin{array}{l}\text { Uso de legendas } \\
\text { interlinguais e } \\
\text { intralinguais }\end{array}$ & $17 / 20$ & $56,48 \%$ & $\begin{array}{l}\text { Danan (1992); Chagas (2005); } \\
\text { Matielo, Colet e D’Ely (2013); } \\
\text { Hsu et al (2013) }\end{array}$ \\
\hline
\end{tabular}

Fonte: Elaborado pelos autores.

Quando solicitados a avaliar a SD da qual tomaram parte, nenhum participante a classificou como "ruim" (Tabela 3). Setenta por cento deles 
a avaliaram como excelente ou ótima. Esses dados nos interessam porque, para que uma ferramenta educacional seja efetiva em sua aplicação, é relevante também que os alunos gostem de utilizá-la. No que concerne ao aprendizado de vocábulos, $45 \%$ dos participantes avaliaram que aprenderam muitas palavras, e outros $45 \%$ avaliaram que aprenderam algumas. Um participante indicou que aprendeu poucas palavras e comentou: "Pelo conhecimento que já tenho, foram poucas as palavras que ainda não tinha conhecimento, porém tive a chance de conhecer novas traduções”.

É importante notar que o aprendizado dos itens lexicais, a partir desse experimento, não está restrito àqueles itens examinados nos Póstestes. Outros vocábulos não usados nos testes podem ter sido adquiridos. Perceba-se, também, que a consciência linguístico-cultural trabalhada a partir da Atividade didática de tradução pode ser considerada uma característica positiva dessa SD, ao passo que rompe com o paradigma biunívoco de tradução que muitos aprendizes de LE ainda possam ter.

TABELA 3 - Avaliação da SD

\begin{tabular}{lcc}
\hline \multicolumn{1}{c}{ Avaliação das atividades } & TDP & PP \\
\hline Excelente & 07 & $35 \%$ \\
Ótimo & 07 & $35 \%$ \\
Bom & 05 & $25 \%$ \\
Regular & 01 & $5 \%$ \\
Ruim & 0 & $0 \%$ \\
\hline Avaliação da aquisição & TDP & PP \\
\hline Muitas palavras & 09 & $45 \%$ \\
Algumas palavras & 09 & $45 \%$ \\
Poucas palavras & 01 & $5 \%$ \\
Nenhuma palavra & 01 & $5 \%$ \\
\hline
\end{tabular}

TDP - Total de Participantes $\quad$ PP - Percentual de participantes

Fonte: Elaborado pelos autores.

\section{Considerações finais}

A aquisição de uma LE é um processo bastante complexo, com múltiplas variáveis envolvidas, fazendo-se necessário ponderar sobre cada uma delas. Em nossa pesquisa, refletimos sobre o uso do texto fílmico legendado combinado a uma atividade de tradução, em uma rotina 
instrucional específica (a SD), como forma de promoção da aquisição de vocabulário em LE. Percebemos, a partir dos resultados, que esse instrumento pedagógico pode contribuir em sala de aula de LE, em diversos contextos instrucionais, como mais uma ferramenta didática.

Como foi visto, a nossa SD traz algumas vantagens ao trabalho de ensino de LE, independentemente do nível de aprendizado dos alunos. Nela, usamos textos contextualizados, podendo inclusive lançar mão de materiais autênticos; os mecanismos de significação dos materiais audiovisuais são múltiplos, sendo facilitadores do entendimento dos aprendizes de LE. Ainda, no momento de produção do TT escrito, o professor de LE, a partir dos questionamentos feitos pelos alunos, tem oportunidade de explanar diversos tópicos da LE, tais como o significado de palavras e aspectos gramaticais da língua.

Além do trabalho de investigação e avaliação do filme enquanto TF e material didático, recomendamos que se use como TF (legendas intralinguais) trechos curtos, sobretudo nos níveis inicias de aprendizado. Sugere-se algo em torno de cem palavras, com a duração das cenas por volta de dois minutos. Busca-se, dessa forma, facilitar a compreensão textual e não cansar os alunos, uma vez que as cenas são reproduzidas pelo menos duas vezes.

Percebemos, entretanto, que o tempo investido pelo professor de LE na elaboração de tarefas que atendam à SD pode ser grande, principalmente no que se refere à investigação textual do TF a ser usado como parte do material didático. Mesmo assim, nota-se também que, uma vez elaborada a SD, esta fica disponível ao professor como parte de um conjunto de atividades que compõem seu acervo de ensino para uso em aulas futuras. Propõe-se, portanto, que os materiais didáticos usados por um professor, em uma SD, possam ser compartilhados com os demais colegas da área, formando-se, assim, um acervo coletivo.

Nesta pesquisa, principalmente com base teórica, sugerimos alguns dos fatores que podem ter influenciado na aquisição de vocabulário dos participantes, como repetição e redundância - características da SD e dos textos multimodais. Porém, não conduzimos, na parte experimental deste estudo, rotinas que pudessem atestar a influência de tais fatores, por exemplo, a repetição do experimento com outros grupos de participantes, ou mesmo com uso de grupos-controle em que as variáveis da SD pudessem ser alteradas. Neste ponto, recomendamos estudos que combinem os três 
tipos de legendas vistas aqui: interlinguais, intralinguais e reversas. Pode-se prever, na metodologia de um estudo como esse, o uso de vários grupos de informantes (grupos experimentais e grupos-controle).

Em nosso estudo, percebemos que o desenho de atividades, de tarefas e de SD são fatores preponderantes à efetividade do uso de filmes legendados, bem como de atividades de tradução, em sala de aula de LE. Desse modo, uma exposição a esse tipo de material audiovisual legendado, no ensino de LE, pode ser mais vantajosa se atrelada a atividades que promovam, também, a aquisição da língua. Nesse sentido, pensar quais e como as atividades serão usadas em conjunto pode ser determinante a sua efetividade.

Argumentamos, baseados no que se lê acima, que essa rotina pedagógica (SD) pode ser adaptada e usada no ensino básico, superior e em cursos de idiomas, e que os ganhos provenientes dela podem ser diversos não só linguísticos, como também de ordem cultural e pragmática. Contudo, nosso foco, neste estudo, foi sua utilização no Ensino Médio, porque entendemos que esta SD pode ajudar a suprir parte da carência lexical em LI que muitos alunos têm (BRITISH COUNCIL, 2014), o que se torna, nesses contextos, um dos muitos desafios que os professores enfrentam. Dessa forma, nossa pesquisa contribui com a proposta de mais uma ferramenta de ensino, já que muitos professores de LI se queixam da falta de recursos para o trabalho em sala de aula (BRITISH COUNCIL, 2015). Ainda, ao contrário da metodologia usada nas pesquisas consultadas, nossa pesquisa se diferencia das demais ao combinar o uso de dois tipos de legendas com o mesmo grupo de participantes, o que pode ter figurado, neste estudo, como um fator preponderante à aquisição de vocabulário em LI.

Com esta pesquisa, espera-se contribuir, ainda, para o fomento de novos estudos que analisem como o uso da legendagem pode ser útil ao processo de ensino e aprendizagem de LE. Neste aspecto, percebeuse, pela literatura consultada, uma carência de pesquisas empíricas que investiguem como os estudantes de LE podem aprender legendando materiais audiovisuais. Esse tipo de pesquisa possibilitaria, a depender da metodologia usada, a exploração de recursos de pesquisa diversos por parte do aluno, como o acesso à internet, a tradutores automáticos, a textos de referência e auxiliares, a dicionários impressos e eletrônicos. Poderia possibilitar, também, o desenvolvimento de projetos de tradução de materiais audiovisuais em grupos de trabalho. Nesses estudos, recomendase a inserção de teorias dos Estudos da Tradução como a perspectiva 
Funcionalista e os Estudos Descritivos, bem como estudos acerca da aquisição de LE que usem abordagens interacionistas.

\section{Referências}

ARAÚJO, V. L. S. The educational use of subtitled films in EFL teaching. In: DÍAZ CINTAS, J. (Ed.). The Didactics of Audiovisual Translation. Amsterdam: John Benjamins, 2008. p. 227-238. Doi: https://doi.org/10.1075/btl.77.22san

BAKHTIN, M. A interação verbal. In: BAKHTIN, M. Marxismo e filosofia da linguagem. 12. ed. São Paulo: Hucitec, 2006. p. 112-130.

BARROS L. S.; PEREIRA U. C.; ANDRADE K. S. Sequência didática: uma proposta metodológica ao ensino de língua materna. Cadernos do CNLF, Rio de Janeiro, v. 18, n. 3, p. 237-259, 2014. Disponível em: <https://goo.gl/ic968q>. Acesso em: 9 set. 2016.

BRISTISH COUNCIL. Demandas de aprendizagem de inglês no Brasil. São Paulo, 2014. BRISTISH COUNCIL. O ensino de inglềs na educação pública brasileira. São Paulo, 2015. CAIMI, A. Subtitling: Language Learner's Needs vs. Audiovisual. In: DÍAZ CARROLL, M.; IVARSSON, J. Code of Good Subtitling Practice. Berlin: European Association for Studies in Screen Translation, 1998. Disponível em: <http:/ /www. transedit.se/code.htm>. Acesso em: 5 set. 2016.

CHAGAS, R. M. F. M. Cinema em sala: os filmes como recursos didáticos para a aula de leitura em LE. 2005. 241 f. Dissertação (Mestrado em Linguística) - Instituto de Letras e Linguística, Universidade Federal de Uberlândia, Uberlândia, 2005. CINTAS, J.; ANDERMAN, G. (Ed.). Audiovisual Translation: Language Transfer on Screen. London: Palgrave McMillan, 2009. p. 240-251. Doi: https://doi. org/10.1057/9780230234581_18

DANAN, M. Reversed Subtitling and Dual Coding Theory: New Directions for Foreign Language Instruction. Language Learning, v. 42, n. 4, p. 497-527, 1992. Disponível em: <https://goo.gl/Zg6Vqt>. Acesso em: 5 set. 2016.

DANAN, M. Captioning and Subtitling: Undervalued Language Learning Strategies. Meta: Translators' Journal, Côte-des-Neiges, MTL, v. 49, n. 1, p. 67-77, 2004. Disponível em: <https://goo.gl/YLwav3>. Acesso em: 5 set. 2016.

DÍAZ CARROLL, M.; IVARSSON, J. Code of Good Subtitling Practice. Berlin: European Association for Studies in Screen Translation, 1998. Disponível em: <http://www.transedit.se/code.htm>. Acesso em: 5 set. 2016. 
DÍAZ CINTAS, J. In search of a theoretical framework for the study of audiovisual translation. In: ORERO, P. (Ed.). Topics in audiovisual translation. Amsterdam: John Benjamins, 2004. p. 21-34. Doi: https://doi.org/10.1075/btl.56.06dia

DÍAZ CINTAS, J. Back to the future in subtitling. In: MUTRA: CHALLENGES OF MULTIDIMENSIONAL TRANSLATION. 2005, Saarbrücken. Proceedings... Saarbrücken: Saarland Museum Modern Gallery, 2005. p. 1-17. Disponível em: <https://goo.gl/1VKtSH>. Acesso em: 29 nov. 2014.

DÍAZ CINTAS, J. Teaching and learning to subtitle in an academic environment. In: DÍAZ CINTAS, J. The didactics of audiovisual translation. Amsterdam: John Benjamins, 2008. p. 89-103. Doi: https://doi.org/10.1075/btl.77.10dia

DÍAZ CINTAS, J.; CRUZ, M. F. Using subtitled video materials for foreign language instruction. In: DÍAZ CINTAS, J. (Ed.). The Didactics of Audiovisual Translation. Amsterdam: John Benjamins, 2008. p. 201-214. Doi: https://doi. org/10.1075/btl.77.20dia

DÍAZ CINTAS, J.; REMAEL, A. Introduction to subtitling. In: DÍAZ CINTAS, J.; REMAEL, A. Audiovisual translation: subtitling. New York: Routledge, 2014. p. 8-16.

FAZILATFAR, A. M.; GHORBANI, S.; SAMAVARCHI, L. The effect of standard and reversed subtitling versus no subtitling mode on 12 vocabulary learning. The Journal of Teaching Language Skills (JTLS), Shiraz, v. 3, n. 1, p. 43-64, 2011. Disponível em: <https://goo.gl/dQbqGH>. Acesso em: 5 set. 2016.

FONSECA, R. C. V. O método científico e a pesquisa. In: FONSECA, R. C. V. Metodologia do trabalho cientifico. Curitiba: Iesde Brasil, 2012. p. 19-26.

FONSECA, S. M. D. Sequência didática para o desenvolvimento de habilidades de produção de enunciados de questões discursivas de provas. Estudos Linguísticos, Campinas, v. 34, p. 1290-1295, 2005. Disponível em: <https://goo.gl/Lmtkfs>. Acesso em: 9 set. 2016

GAMBIER, Y. Multimodality and Audiovisual Translation. In: MUTRA: AUDIOVISUAL TRANSLATION SCENARIOS: CONFERENCE PROCEEDINGS, 2006. Copenhagen. Proceedings... Copenhagen: MuTra, 2006. p. 1-9. Disponível em:<https://goo.gl/okuunU>. Acesso em: 29 nov. 2014.

GEORGAKOPOULOU, P. Subtitling for the DVD Industry. In: DÍAZ CINTAS, J:; ANDERMAN, G. (Ed.). Audiovisual translation: language transfer on screen. London: Palgrave McMillan, 2009. p. 21-35. Doi: https://doi.org/10.1057/9780230234581_2 GIL, A. C. Como classificar as pesquisas. In: GIL, A. C. Como elaborar projetos de pesquisa. 4. ed. São Paulo: Atlas, 2002. p. 41-58. 
GOMES, F. W. B. O uso de filmes legendados como ferramenta para o desenvolvimento da proficiência oral de aprendizes de língua inglesa. 2006. 132 f. Dissertação (Mestrado em Linguística Aplicada) -Universidade Estadual do Ceará, Fortaleza, 2006.

HSU, C. K. et al. Effects of Video Caption Modes on English Listening Comprehension and Vocabulary Acquisition Using Handheld Devices. Journal of Educational Technology \& Society, Kaohsiung, v. 16, n. 1, p. 403-414, 2013. Disponível em: <https://goo.gl/1rsYBY>. Acesso em: 5 set. 2016.

KRASHEN, S. Principles and Practice in Second Language Acquisition. Los Angeles: University of Southern California, 2009. Disponível em: <https://goo.gl/ NebCq9>. Acesso em: 21 maio 2016. 202 p.

KRESS, G.; VAN LEEUWEN, T. Introduction: the grammar of visual design. In: KRESS, G.; VAN LEEUWEN, T. Reading images: The Grammar of Visual Design. 2. ed. Abingdon: Taylor \& Francis Group, 2006. p. 1-15. Doi: https://doi. org/10.1007/3-540-30619-6_1

KRUGER, J.-L. Subtitler training as part of a general training programme in the language professions. In: DÍAZ CINTAS, J. (Ed.). The Didactics of Audiovisual Translation. Amsterdam: John Benjamins, 2008. p. 71-88. Doi: https://doi. org/10.1075/btl.77.09kru

MÃOS talentosas (Gifted Hands). Direção: Thomas Carter. Produção: Bruce Stein, Erin Keating, Margaret Loesch. Intérpretes: Cuba Gooding Jr., Kimberly Elise, Aunjanue Ellis. Culver City, CA: Sony Pictures, 2009. 1 DVD (90 min).

MAROQUI, V. S.; PAIVA, M. A. V.; FONSECA, C. O. Sequências didáticas como recurso pedagógico na formação continuada de professores. In: ENCONTRO CAPIXABA DE EDUCAÇÃO MATEMÁTICA, 10., Vitória, 2015. Vitória: Ifes; Ufes, 2015. p. 1-9.

MATIELO, R.; COLLET, T.; D’ELY, R. C. S. F. The effects of interlingual and intralingual subtitles on vocabulary learning by Brazilian EFL learners: an exploratory study. Revista Intercâmbio, São Paulo, v. XXVII, p. 83-99, 2013. Disponível em: <https://goo.gl/rBSsNP>. Acesso em: 31 maio 2016.

NEVES, J. Language awareness through training in subtitling. In: ORERO, P. (Ed.). Topics in audiovisual translation. Amsterdam: John Benjamins, 2004. p. 127-140. Doi: https://doi.org/10.1075/btl.56.14nev

NORD, C. Translating as a purposeful activity: functionalist approaches explained. Shanghai: Shanghai Foreign Language Education Press, 2001.

NORD, C. Text analysis in translation: theory, methodology, and didactic application of a model for translation-oriented text analysis. 2 ed. New York: Rodopi, 2005. 
NORD, C. Loyalty and fidelity in specialized translation. Confluências: Revista de Tradução Científica e Técnica, Lisboa, n. 4, p. 29-41, 2006a. Disponível em: <https://goo.gl/VTwNgH>. Acesso em: 5 set. 2016.

NORD, C. Translating for communicative purposes across culture boundaries. Journal of Translation Studies, Hong Kong, v. 9, n. 1, p. 43-60, 2006b. Disponível em: <https://goo.gl/3UTYME>. Acesso em: 5 set. 2016.

NORD, C. El funcionalismo en la enseñanza de traducción. Mutatis Mutandis: Revista Latinoamericana de Traducción, Medellín, v. 2, n. 2, p. 209-243, 2009. Disponível em: <https://goo.gl/z2W9M3>. Acesso em: 5 set. 2016.

NORD, C. Las funciones comunicativas en el proceso de traducción: un modelo cuatrifuncional. Núcleo, Caracas, v. 27, p. 239-255, 2010. Disponível em: <https:/ / goo.gl/y7Dnve>. Acesso em: 5 set. 2016.

NORD, C. Quo vadis, functional translatology? Target, Amsterdam, v. 24, n. 1, p. 26-42, 2012.

OLIVEIRA FILHO, L. Utilização da legendagem intralinguística no desenvolvimento da proficiência oral em língua francesa. 2008. 132 f. Dissertação (Mestrado em Linguística Aplicada) - Universidade Estadual do Ceará, Fortaleza, 2008.

PAVESI, M.; PEREGO, E. Tailor-made interlingual subtitling as a means to enhance second language acquisition. In: DÍAZ CINTAS, J. (Ed.). The Didactics of Audiovisual Translation. Amsterdam: John Benjamins, 2008. p. 215-226. Doi: https:/ / doi.org/10.1075/btl.77.21pav

PERETTI, L.; TONIN DA COSTA, G. M. Sequência didática na matemática. Revista de Educaşão do Ideau, Alto Uruguai, v. 8, n. 17, p. 1-14, 2013. Disponível em: $<$ https://goo.gl/vtrAAB >. Acesso em: 9 set. 2016.

REISS, K. Type, kind and individuality of text: decision making in translation. Translated by Susan Kitron. In: VENUTI, L. (Ed.). The Translation Studies Reader. New York: Routledge: 2004. p. 160-171.

RIBEIRO, F. C. A. Papel do estágio supervisionado na construção identitária do professor de LI: relato de experiência com uma sequência didática. 2013. 34 f. Trabalho de Conclusão de Curso (Licenciatura Plena em Letras - Inglês) - Universidade Estadual da Paraíba, Campina Grande, 2013.

SKUGGEVIK, E. Teaching Screen Translation: The Role of Pragmatics in Subtitling. In: DÍAZ CINTAS, J.; ANDERMAN, G. (Ed.). Audiovisual Translation: Language Transfer on Screen. London: Palgrave McMillan, 2009. p. 197-213. Doi: https://doi.org/10.1057/9780230234581_15 
SNELL-HORNBY, M. The turns of Translation Studies. In: GAMBIER, Y.; DOORSLAER, L. (Ed.). Handbook of translation studies. Amsterdam: John Benjamins, 2010. v. 1, p. 366-370. Doi: https://doi.org/10.1075/hts.1.the1

SOUSA, B. B. A. A. L. Aquisição vocabular por meio de filmes legendados: o uso da tradução numa sequência didática. 2016. 224 f. Dissertação (Mestrado em Estudos da Tradução) - Universidade Federal do Ceará, Fortaleza, 2016. Disponível em: $<$ https://goo.gl/42qirA>. Acesso em: 26 jan. 2017.

VERMEER, H.-J. Skopos and Commission in Translational Action. Translated by Andrew Chesterman. In: VENUTI, L. (Ed.). The Translation Studies Reader. New York: Routledge: 2004. p. 221-232.

ZABALA, A. A prática educativa: como ensinar. Porto Alegre: Artmed, 1998. 221 p. ZABALBEASCOA, P. The nature of the audiovisual text and its parameters. In: Díaz Cintas, J. The Didactics of Audiovisual Translation. Amsterdam: John Benjamins, 2008. p. 21-37. DOI: https://doi.org/10.1075/btl.77.05zab

Data de submissão: 16/04/2017. Data de aprovação: 31/10/2017. 